\title{
Retrospective study of tumor and tumor like conditions of ovary from a rural hospital in Kerala
}

\author{
H. Valson ${ }^{1 *}$, Satish Arakeri ${ }^{2}$, Dally Maria Davis ${ }^{1}$, Divya S. ${ }^{1}$
}

${ }^{1}$ Department of Obstetrics and Gynecology, ${ }^{2}$ Department of Pathology, DMWIMS, Wayanad, Kerala, India

Received: 15 June 2017

Accepted: 20 June 2017

\section{*Correspondence:}

Dr. H. Valson,

E-mail: h.valson@gmail.com

Copyright: (C) the author(s), publisher and licensee Medip Academy. This is an open-access article distributed under the terms of the Creative Commons Attribution Non-Commercial License, which permits unrestricted non-commercial use, distribution, and reproduction in any medium, provided the original work is properly cited.

\begin{abstract}
Background: Ovarian tumor and tumor like conditions are seen in women from early childhood to post-menopausal age. The ovaries are a pair of female sex glands responsible for the germ cell maturation, storage and release; cyclically. It also plays an important role in steroidogenesis. The ovaries are a totipotential structure and hence, neoplasms from all 3 germinal layers can be seen arising from it and manifesting clinically as ovarian tumors and tumor like conditions with its occurrence more during the late reproductive life. Ovarian tumors represent about $30 \%$ of all cancers of the female genital system. They manifesting in a wide spectrum of clinical, morphological and histological features.

Methods: This is retrospective observational study where analysis of all cases which were encountered surgically during the period Mar 2012 to Mar 2017. The cases diagnosed as ovarian tumors were subjected to thorough investigation by CA125, ultrasound (USG) abdomen and pelvis and Computerised Tomography (CT) scan. Emergency presentations with twisted cysts were operated in emergency setting and histopathological examination (HPE) done to identify the nature of tumor. IHC was done wherever necessary to sub classify and confirm the histological diagnosis. Surgeries were done either by conventional laparotomy or by laparoscopy.

Results: We have analyzed 175 cases retrospectively after histopathological diagnosis. The commonest lesions were ovarian cysts, out of which 63 cases (36\%) were simple serous cyst adenomas followed by mucinous cyst adenomas 30 cases $(17.14 \%)$. Germ cell tumors with struma ovarii were 34 cases $(19.42 \%)$. The interesting part of the study was that we had a very high incidence of large endometriomas diagnosed as ovarian cysts before surgery 16 cases $(9.4 \%)$. Two cases $(1.14 \%)$ of ovarian malignancy were detected.

Conclusions: The above study has revealed a spectrum of ovarian tumors over a wide age range from adolescent to late reproductive to menopausal and late menopausal age group. The incidence of malignancy was (1.14\%).
\end{abstract}

Keywords: Cystadenomas, Dermoid cysts, Endometriomas, Fibromas

\section{INTRODUCTION}

The prevalence of ovarian cysts and tumor like conditions has been reported to be between 2 to $4 \%$ among gynecological admissions. About $95 \%$ of these tumors have been found to be benign. Ovarian malignancies represent the greatest clinical challenge of all the gynecological malignancies. During the reproductive years most of the ovarian tumors encountered are benign. About $2 / 3$ of the ovarian tumors are encountered in this group only. ${ }^{1}$ The chance that an ovarian tumor is malignant in a patient younger than 45 years is 1 in 15 . The pathology of ovarian tumors and tumor like conditions is one of the most complex areas in 
gynecology. This is because the ovary gives rise to a great range and variety of tumors than any other organ in the body. The tissue from which the ovarian tumor arises is often uncertain and the mode of development of the presumptive tissue is often disputed. ${ }^{2}$

Ovarian tumors have become an important cause of female gynecological cancers which remain silent for a long time before they become symptomatic. They are important not only because of the large variety of neoplastic entities but more so because they have gradually increased the mortality rate due to female genital cancers. The exact incidence in south India is not known but ovarian cancer is the one of the common cancer among females of India and continues to present at an advanced stage. ${ }^{3}$ Japan and Asian countries have rates of 2-6.5 new cases per 100,000 women per year. ${ }^{4}$ Ovarian carcinoma represents the sixth most common female cancer and the fourth leading cause of death due to cancers in women and is seen predominantly after 3rd decade of life. ${ }^{5}$

Ovarian cysts of benign nature may occur at any point in the life but they are most common during childbearing age and constitute about $90 \%$ of ovarian tumors. ${ }^{6}$ Most benign tumors are cystic and finding of solid elements make malignancy more likely. Ovarian tumors are generally difficult to detect until they are advanced in stage or size, as the symptoms are vague and manifest over time. Determination of various histologic patterns of ovarian tumors is very important in diagnosis, prognosis as well as treatment of ovarian tumors. Prognosis of the tumors can also be predicted from the degree of differentiation of the tumors.

Primary tumors are classified into surface epithelial tumors, germ cell tumors (both primitive germ cell and mature teratomas and also monodermal like struma ovarii, sex cord stromal tumors like granulosa stromal cell and thecomas. Surface epithelial tumors are most common. The stage and laterality of the tumor also indicates their nature for example, tumors in the sex cord stromal category are almost always confined to a single ovary. On the other hand, approximately $65 \%$ of the metastatic tumors are bilateral (krukenberg). In this study, we have analyzed the spectrum of ovarian tumors and histopathological patterns.

\section{METHODS}

The data of all ovarian tumors operated in DM WIMS College and Hospital, between Mar 2012 to Mar 2017 were obtained and analysed. The inclusion criteria were all cases of operable ovarian tumors which were subjected to surgery. A total of 175 operated cases were analysed. The data collected included age at presentation, symptoms and clinical presentation, CA 125 levels, AFP levels, USG and CT findings and HPE report. This data was tabulated and analysed using suitable statistical tool.The analysis was done to study the spectrum of the various types of ovarian lesions in the different age groups, HPE correlation to classify and grade the tumors histologically.

\section{RESULTS}

Maximum numbers of cases (54) were in the age group of 41-50yrs (Table 1).

Table 1: Age wise distribution of all lesions both benign and malignant.

\begin{tabular}{|lll|}
\hline Age in years & No. of cases & $\%$ \\
\hline $10-20$ & 10 & 5.71 \\
\hline $21-30$ & 24 & 13.71 \\
\hline $31-40$ & 40 & 22.85 \\
\hline $41-50$ & 54 & 30.85 \\
\hline $51-60$ & 25 & 14.28 \\
\hline $61-70$ & 15 & 8.57 \\
\hline $71-80$ & 07 & 4 \\
\hline
\end{tabular}

Maximum cases were epithelial cystadenomas and two cases of malignancy, one is yolk sac and other granulosa tumor (Table 2).

Table 2: Spectrum of ovarian tumors and tumor like conditions (after HPE correlation).

\begin{tabular}{|lll|}
\hline Type of ovarian lesion & No. of cases & $\%$ \\
\hline Serous cyst adenomas & 63 & 36 \\
\hline Mucinous cyst adenomas & 30 & 17.14 \\
\hline $\begin{array}{l}\text { Mature teratomas } \\
\text { (cystic and solid) }\end{array}$ & 30 & 17.14 \\
\hline Theca cell and fibromas & 06 & 3.42 \\
\hline Struma ovarii & 03 & 1.71 \\
\hline $\begin{array}{l}\text { Yolk sac (germ cell) } \\
\text { malignant }\end{array}$ & 01 & 0.57 \\
\hline Adult granulosa (malignant) & 01 & 0.57 \\
\hline endometriomas & 16 & 9.14 \\
\hline Simple cysts & 25 & 14.28 \\
\hline
\end{tabular}

Total abdominal hysterectomy (TAH) with bilateral salpingoophorectomy (BSO) and omentectomy was done in 6 cases, cystectomy in 7 cases TAH with BSO in 53 cases (Table 3).

Table 3: Surgery performed.

\begin{tabular}{|lll|}
\hline $\begin{array}{l}\text { Type of } \\
\text { operation }\end{array}$ & $\begin{array}{l}\text { Conventional } \\
(\text { open })\end{array}$ & Laparoscopic \\
\hline $\begin{array}{l}\text { TAH+BSO+ } \\
\text { omentectomy }\end{array}$ & 06 & nil \\
\hline TAH+BSO & 53 & 11 \\
\hline $\begin{array}{l}\text { Salpingo- } \\
\text { ophorectomy }\end{array}$ & 28 & 40 \\
\hline $\begin{array}{l}\text { Cystectomy } \\
\text { Total }\end{array}$ & 07 & 31 \\
\hline
\end{tabular}


The incidence of ovarian neoplasm was compared with the other studies (Table 4 and 5) and present study results are comparable to their studies.
The incidence of serous and mucinous cystadenomas are comparable other authors studies (Table 6).

Table 4: Comparative incidence of all ovarian neoplasms.

\begin{tabular}{|llllll|}
\hline Ovarian tumors & Our study & Pilli et al & Gupta et al & Couta F et al & R Jha et al \\
\hline Surface epithelial & $53.14 \%$ & $70.9 \%$ & $48.8 \%$ & $68.81 \%$ & $52.2 \%$ \\
\hline Sex cord & $4 \%$ & $6 \%$ & $6.75 \%$ & $8.3 \%$ & $3.1 \%$ \\
\hline Germ cell & $21.14 \%$ & $21.2 \%$ & $23.9 \%$ & $20.39 \%$ & $42.2 \%$ \\
\hline metastatic & nil & $2 \%$ & $0.7 \%$ & $1.46 \%$ & $2.4 \%$ \\
\hline malignant & $1.14 \%$ & nil & nil & nil & nil \\
\hline
\end{tabular}

Table 5: Comparative study of the incidence of serous and mucinous cysts.

\begin{tabular}{|lll|}
\hline Ovarian tumour & Serous & Mucinous \\
\hline Present study & $36 \%$ & $17.14 \%$ \\
\hline Kumar S et al & $46.7 \%$ & $16.3 \%$ \\
\hline Zaman S et al & $43.2 \%$ & $20 \%$ \\
\hline Kuldeepa et al & $33.82 \%$ & $32.5 \%$ \\
\hline
\end{tabular}

Table 6: Histopathological grading of ovarian tumors operated.

\begin{tabular}{lllll|}
$\begin{array}{l}\text { Histo- } \\
\text { pathological } \\
\text { classification }\end{array}$ & Benign & $\begin{array}{l}\text { Border- } \\
\text { line }\end{array}$ & Malignant & total \\
\hline $\begin{array}{l}\text { Serous } \\
\text { Mucinous }\end{array}$ & 63 & 0 & 0 & 63 \\
\hline $\begin{array}{l}\text { Germ cell } \\
\begin{array}{l}\text { Teratomas } \\
\text { with struma } \\
\text { ovarii, yolk }\end{array}\end{array}$ & 32 & 0 & 0 & 30 \\
sac) & 06 & 0 & 01 & 34 \\
\hline Sex cord & 06 & 01 & 07 \\
\hline
\end{tabular}

Operative and microscopic images were shown in Figure 1-5. One hundred and seventy-five cases of ovarian cysts, tumor, and tumor like lesions were studied.

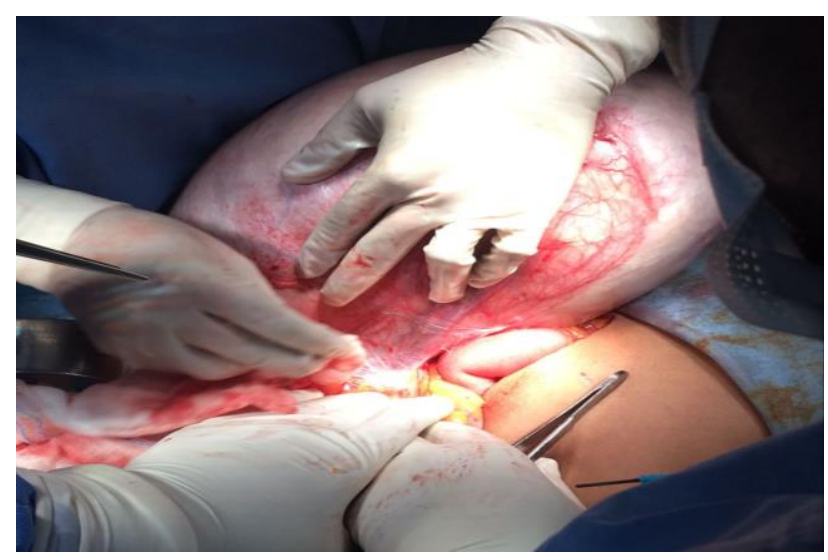

Figure 1: Operative photograph of large ovarian tumor arising from left ovary.

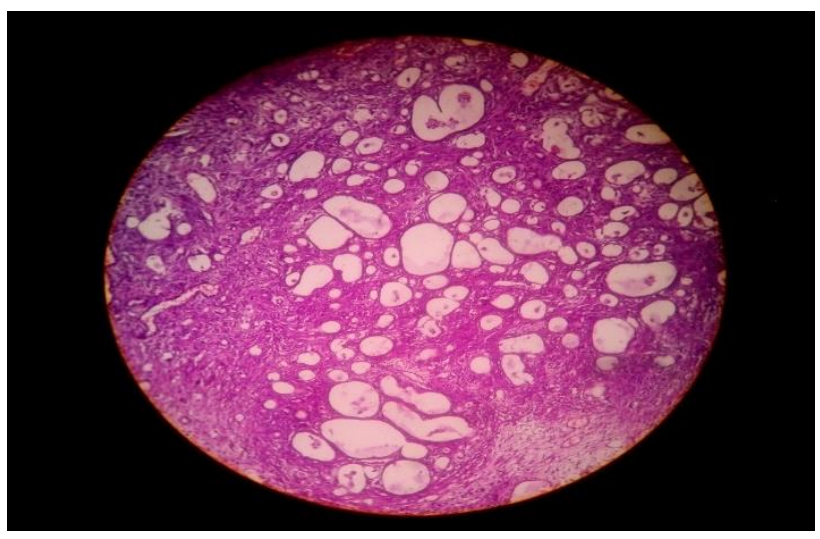

Figure 2: Section studied shows multiple microcyst with pleomorphic tumor cells infiltrating exhibits features of yolk sac tumor ( $\mathrm{H}$ and $\mathrm{E}$ stain $40 \mathrm{x}$ ).

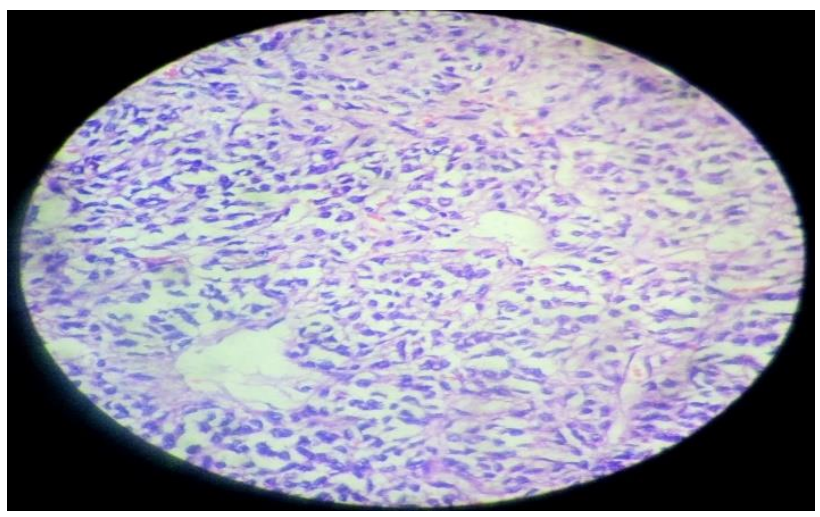

Figure 3: Microscopic appearance of granulosa cell tumor (40x, $H$ and $E$ stain).

Of these 175 cases, 172 cases were benign and 1 case was borderline and 2 cases were malignant lesions.

Histologically surface epithelial tumors; benign cyst adenomas (serous and mucinous) were the commonest, 93 cases $(53.14 \%)$ ) followed by germ cell tumors ie mature teratomas, struma ovarii 34 cases $(9.14 \%)$ and one case of yolk sac tumor, sex cord stromal tumors 7 (8.3\%). Immunohistochemistry was done in 3 cases of struma ovarii and yolk sac tumor. 


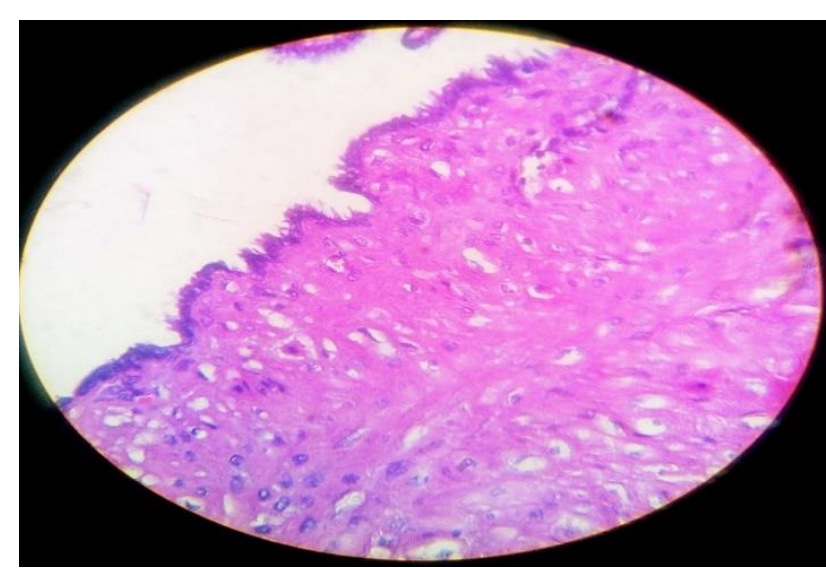

Figure 4: Microscopic appearance of serous cystadenoma lined by ciliated epithelium $(40 x, \mathrm{H}$ and E stain).

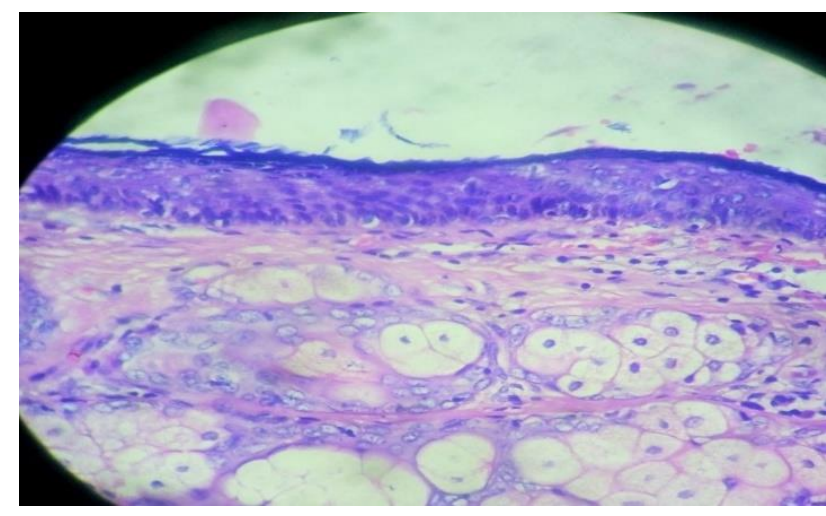

Figure 5: Microscopic appearance of dermoid cyst lined by stratified squamous epithelium with adnexal strucures (100x, H and E stain).

\section{DISCUSSION}

From the total 175 cases, benign epithelial tumors constituted the most $(53.14 \%)$ comparable with some studies. Benign lesions were seen more in age group 21 to 40 yrs. Majority of ovarian tumors belonged to surface epithelial category $(53.14 \%)$ followed by germ cell category (19.42\%) and compared with other studies (Table-4). Among surface epithelial tumors, serous cyst adenoma were more common followed by mucinous cyst adenoma. Similar results were shown in studies by Mandal et al and Ameena Ashroff et al. ${ }^{7,8}$

We categorized surface epithelial tumors into subtypes based on microscopic examination and correlating with gross clinical and radiological findings. In case of serous cyst adenoma, lining of cysts was single layer of cuboidal epithelium whereas papillae of serous cyst adenocarcinoma showed stratification of epithelial lining with nuclear atypia, mitotic activity, and stromal invasion. In case of mucinous cyst adenoma, cyst lining was single layer of tall, columnar, clear, mucincontaining epithelium and uniform basally arranged nuclei. Ovarian tumors were found to affect women in a wide age range with peak incidence in the 21- 40 Yrs. age group. Majority of the tumors in our study were unilateral. $12 \%$ of serous tumors and $4 \%$ of mucinous tumors were bilateral. Incidence of germ cell tumors was correlated with other studies except with the study of $\mathrm{R}$ Jha et al (Table 4) who showed $42 \%$. Frequency of sex cord stromal tumors was comparable with other studies (Table 4). Ovarian cancers are called a "Silent Killer" as in most of the primary ovarian tumors, they remain asymptomatic until the advanced stage. However, histological study of tumor is still today a gold standard method to provide valuable baseline information regarding frequency and pattern of ovarian tumors in our rural settings.

Distinguishing benign from malignant ovarian tumors using currently available diagnostic modality is at times difficult were in IHC methods may be required especially in sex cord stromal tumors and germ cell, teratomas with neural or thyroid elements or yolk sac tumors. ${ }^{9}$ Benign ovarian tumors and tumor like condition are frequently encountered in the reproductive and late reproductive period of a woman's life. Incidence was found to be maximum in late reproductive age group. Most women with ovarian cysts are asymptomatic and symptoms such as pain and vague pressure sensation are common. In present study, the tumors were largely asymptomatic, with nearly $70 \%$ patients presenting with no symptoms or vague abdominal discomfort. In some cases, the finding was incidental when it was associated with fibroid or AUB However we could not find any significant association between these lesions and the ovarian tumors. The majority of tumors were found to be serous cyst adenoma (36\%), mucinous cyst adenoma (17.14\%), and dermoid tumors $(18.85 \%)$ the most frequent germ cell tumor. Similar incidences were noted in a study by Giurgea NL et al. from 116 cases, 57 (49.1\%) were benign which included 37 cases of serous tumors (64.9\%) and 20 cases of mucinous types $(35 \%) .{ }^{10}$ laterality analysis did not yield any statistically significant findings. But some of the cases were bilateral which is not very common in benign ovarian tumors. Most of the medical co-morbid conditions that the study found probably were because of the patients in later half of their reproductive life like diabetes mellitus, chronic hypertension, obesity which were independent entities without bearing any relation to the occurrence of ovarian tumors. Most of them were encountered in the peri and post-menopausal age group and not much of significance could be attached to it except for the pre-operative and post-operative management.

\section{CONCLUSION}

Benign ovarian tumors were more common than malignant ones across all age groups. Surface epithelial tumors were the most common histopathological type of ovarian tumor. Due to vague symptoms, patients present late and hence prognosis becomes poor by the time ovarian malignancy is diagnosed. Benign ovarian tumors 
form a very important clinical entity for a gynecologist. Differentiation between a benign and malignant tumor is many a times difficult and histopathology with IHC is the only definitive way to confirm it post-surgery for further adjuvant therapy in potentially malignant and malignant tumors after cytoreductive surgery.

Funding: No funding sources Conflict of interest: None declared

Ethical approval: The study was approved by the Institutional Ethics Committee

\section{REFERENCES}

1. Jonathan S. Berek; Berek and Novak's Gynaecology 15th ed, Lippincott Williams \& Wilkins; 2011.

2. Kumar P, Malhotra N. Jeffcoate's Principles of Gynaecology. 7th ed. Jaypee Brothers Medical Publishers (P) Ltd;2008.

3. Parveen S, Ilyas N, Asghar S. Patterns of care for ovarian cancer: Patients at Institute of Nuclear Medicine and Oncology (INMOL) Lahore. Specialist J Pak Med Sci. 1999;15:209-15.

4. Murad A. Ovulation induction and ovarian tumours: the debate continues. J Pak Med Assoc. 1998;48:353-6.

5. TortoleroL, Mitchell FM, Rhodes HE. Epidemiology and screening of ovarian cancer. Obstet Gynecol Clin North Am. 1994;21:63-75.
6. Day N.E, Krishnan E. Epidemiology of gynaecological cancers. Gynecology by Shaw R W. 2nd ed. Edinburgh: Churchill Living Stone; 1997:477-87.

7. Mondal SK, Banyopadhyay R, Nag DR, Roychowdhury S, Mondal PK, Sinha SK. Histologic pattern, bilaterality, and clinical evaluation of 957 ovarian neoplasms: a 10-year study in a tertiary care hospital of Eastern India. J Cancer Res Ther. 2011;7(4):433-7.

8. Shaikh AS, Akram AI, Kamal F, Ah N. The relative frequency and histopathological pattern of ovarian masses. Biomedica 2012;28:98-102.

9. Hoffman B, Schorge J, Schaffer J, Halvorson L, Bradshaw K, Cunningham F. Williams Gynecology. 2 nd ed. McGraw-Hill Professional;2012.

10. Giurgea NL, Pitrop M, Mihailovici MS. Serous and mucinous epithelial ovarian tumors--a clinicopathologic study of 116 cases. Rev Med Chir Soc Med Nat Iasi. 2012;116(2):389-94.

Cite this article as: Valson $\mathrm{H}$, Arakeri S, Davis DM, Divya S. Retrospective study of tumor and tumor like conditions of ovary from a rural hospital in Kerala, India. Int J Reprod Contracept Obstet Gynecol 2017;6:3275-9. 